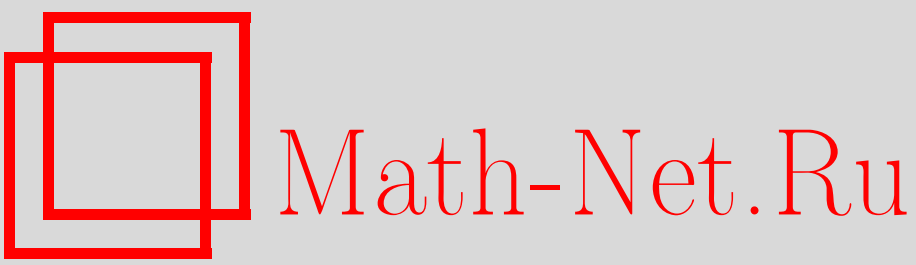

Я. Н. Шитов, Решение задачи о спектрах матриц, заданных шаблоном знаков, Матем. заметки, 2021, том 110, выпуск 6, 954

DOI: https://doi.org/10.4213/mzm13220

Использование Общероссийского математического портала Math-Net.Ru подразумевает, что вы прочитали и согласны с пользовательским соглашением

http://www .mathnet.ru/rus/agreement

Параметры загрузки :

IP : 54.92 .164 .108

26 апреля 2023 г., 11:20:09

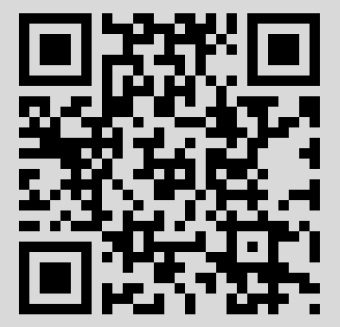




\section{Решение задачи о спектрах матриц, заданных шаблоном знаков}

\section{Я. Н. Шитов}

Ключевые слова: матрицы, собственные значения, шаблон знаков.

DOI: https://doi.org/10.4213/mzm13220

Данная заметка посвящена активно изучаемой теме спектральных свойств вещественных матриц, заданных набором знаков соответствующих элементов [1], [2].

Пусть $A$ - вещественная матрица размера $n \times n$. Обозначим через $s_{k} \subseteq\{+,-, 0\}$ множество всех знаков главных миноров порядка $k=1,2, \ldots, n$ в матрице $A$, а получившийся набор $\left(s_{1}, \ldots, s_{n}\right)$ назовем sepr-последовательностъю матрицы $A$. Предположение 3.1 в работе [2] состояло в том, что любая матрица $X$, в которой на месте $(i, j)$ стоит одно из значений $0, x_{i j},-x_{i j}$, имеет одну и ту же sepr-последовательность для всех положительных значений переменных в том и только том случае, если для любого $k$ выполнено одно из следующих условий:

(a) знак каждого отдельно взятого главного минора порядка $k$ не зависит ни от выбора положительных значений переменных;

(б) существуют три главных минора порядка $k$, каждый из которых также принимает значения лишь одного знака, и для этих трех миноров все соответствующие знаки различны.

Легко видеть, что для любых положительных значений переменных матрица

$$
\mathcal{A}=\left(\begin{array}{cccccc|ccc}
0 & 0 & 0 & 0 & 0 & 0 & a_{1} & 0 & 0 \\
0 & 0 & 0 & 0 & 0 & 0 & 0 & a_{2} & 0 \\
0 & 0 & 0 & 0 & 0 & 0 & 0 & 0 & a_{3} \\
0 & 0 & 0 & 0 & 0 & 0 & 0 & 0 & a_{4} \\
0 & 0 & 0 & 0 & 0 & 0 & 0 & 0 & a_{5} \\
0 & 0 & 0 & 0 & 0 & 0 & 0 & 0 & a_{6} \\
\hline b_{1} & b_{2} & 0 & 0 & 0 & 0 & 0 & 0 & 0 \\
b_{3} & b_{4} & 0 & 0 & b_{5} & -b_{6} & 0 & 0 & 0 \\
0 & b_{7} & b_{8} & -b_{9} & b_{10} & b_{11} & 0 & 0 & 0
\end{array}\right)
$$

дает $s_{k}=\{0,+,-\}$ при $k=2,4,6$ и $s_{k}=\{0\}$ в противном случае. Тем не менее, всякий главный минор матрицы $\mathcal{A}$ порядка 6 , не являющийся тождественно нулевым, содержит слагаемые разных знаков, и поэтому оба условия (а), (б) нарушаются при $k=6$. Таким образом, предположение 3.1 из работы [2] неверно, и алгоритмические вопросы распознавания единственности sepr-последовательности остаются открытыми.

\section{СПИСОК ЦИТИРОВАННОЙ ЛИТЕРАТУРЫ}

[1] J.H. Drew, C.R. Johnson, D. D. Olesky, P. van den Driessche, Linear Algebra Appl., 308:1-3 (2000), 121-137. [2] L. Hogben, J. C.-H. Lin, D. D. Olesky, P. van den Driessche, Linear Multilinear Algebra, 68:10 (2020), 2044-2068.

Я. Н. Шитов

E-mail: yaroslav-shitov@yandex.ru
Поступило

13.07.2021

После доработки

10.08.2021

Принято к публикации

11.08.2021 